\title{
Appendix 1: interviews
}

Interviews cited in the book, including informants' dates of birth and the month and year of each interview:

\#1: b. 1947; February 1996

\#2: b. 1959; February 1996

\#3: b. 1944; March 1996

\#4: b. 1936; March and July 1996

\#5: b. 1949; March 1996

\#6: b. 1946; April 1996

\#7: b. 1943; May 1996

$\# 8$ a: b. 1948; May 1996

$\# 8$ b: b. 1947; May 1996

\#9: b. 1958; May 1996

$\# 10$ : b. 1957; June 1996

\#11a: b. 1946; July 1996

\#11b: b. 1944; July 1996

\#11c: b. 1945; July 1996

\#12: b. 1947; August 1996

\#13: b. 1941; August 1996

\#14: b. 1956; August 1996, and untaped conversation, June 1996

\#15: b. 1946; January 1997

\#16: b. 1958; January 1997

\#17: b. 1958; February 1997

\#18: b. 1961; March 1997

\#19: b. 1944; March 1997

\#20: b. 1945; March 1997

\#21: b. 1945; April 1997

\#22: b. 1943; August 1996 (untaped) 